\title{
USO DA VEGETACCÃO E DOS SOLOS EM ÁREAS SUSCEPTÍVEIS À DESERTIFICAÇÃO NA PARAÍBA/BRASIL
}

\author{
BARTOLOMEU ISRAEL SOUZA \\ Universidade Federal da Paraíba
}

\section{Introdução}

A desertificação é entendida oficialmente pela Organização das Nações Unidas como "[...] a degradação da terra nas zonas áridas, semiáridas e sub-húmidas secas, resultante de vários factores, incluindo as variações climáticas e as actividades humanas" (CCD, 1995:13).

Sobre a degradação da terra, a Convenção das Nações Unidas de Combate à Desertificação (CCD, 1995:14) compreende esse fenômeno como

(...) a redução ou perda, nas zonas áridas, semi-áridas e subhúmidas secas, da produtividade biológica ou econômica e da complexidade das terras agrícolas de sequeiro, das terras agrícolas de regadio, das pastagens naturais, das pastagens semeadas, das florestas ou das áreas com arvoredo disperso, devido aos sistemas de utilização das terras ou a um processo ou combinação de processos, incluindo os que resultam da actividade do homem e das suas formas de ocupação do território, tais como:

(i) A erosão do solo causada pelo vento e/ou pela água;

(ii) A deterioração das propriedades físicas, químicas e biológicas ou econômicas do solo e,

(iii) A destruição da vegetação por períodos prolongados.

Dentre outros países, o Brasil apresenta parte do seu território susceptível à ocorrência desse tipo de fenômeno, tendo em vista a prática de determinados usos do solo em condições de climas secos, presentes num vasto território da Região Nordeste e numa pequena porção da Região Sudeste, localizada ao norte do Estado de Minas Gerais e nordeste do Espírito Santo (BRASIL, 2004). 
A degradação em questão ocorre ou é passível de ocorrer nas diversas regiões de clima seco do mundo, principalmente em virtude de determinadas formas de manejo a que são submetidos os recursos naturais existentes, em particular a vegetação e os solos, estimando-se que mais de 100 países já estejam afetados e cerca de um bilhão de pessoas sofram direta e indiretamente os seus efeitos (ROXO, 2006).

Este trabalho pretende apresentar alguns dos resultados do projeto de pesquisa intitulado "Território, desenvolvimento rural e práticas agrícolas sustentáveis em áreas com risco de desertificação no Brasil, Portugal e Cabo Verde"1. O objetivo geral deste projeto é comparar as ações e políticas de desenvolvimento territorial rural, levadas a efeito por órgãos governamentais, não governamentais e pela sociedade civil organizada que tenham como resultados a realização de práticas agrícolas sustentáveis e ações sociais solidárias em regiões inseridas nas áreas com risco de desertificação (ASDs) no Brasil (Região Nordeste), em Portugal (Região da Beira Interior) e em Cabo Verde (Ilha de Santiago).

As ASDs pesquisadas nos três países, mesmo apresentando especificidades do ponto de vista da variedade dos climas secos dominantes e também das formas em que a população organiza os usos das suas terras, têm em comum o fato de apresentarem importantes porções desses espaços onde a desertificação já se encontra presente, ao mesmo tempo em que são alvo de diversas ações que demonstram capazes de serem reproduzidas nos três países e apresentarem resultados positivos. Dessa forma, torna-se importante o conhecimento e divulgação dessas experiências.

Neste artigo, destacaremos os efeitos dos diferentes usos das terras sobre a vegetação e as relações com a fertilidade dos solos em algumas áreas pesquisadas no Estado da Paraíba, nos municípios de Matureia, Soledade e São João do Tigre (Figura 1).

\footnotetext{
${ }^{1}$ Financiado pelo Programa de Cooperação em Matéria de Ciências Sociais para a Comunidade dos Países de Língua Portuguesa (Programa Ciências Sociais - CPLP), edital CNPQ n ${ }^{\circ} 013 / 2008$.
} 


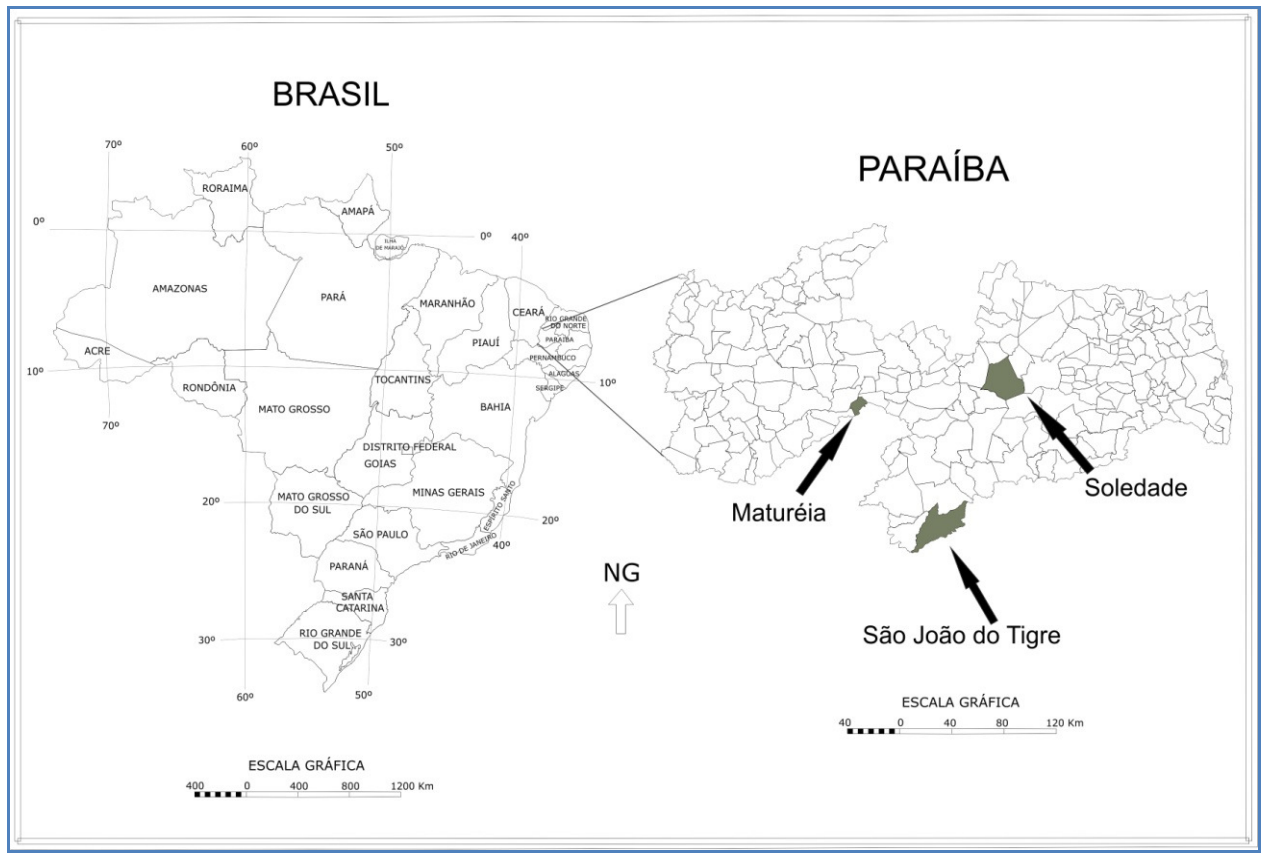

Figura 1. Localização dos municípios estudados na Paraíba

Esses municípios foram escolhidos para o desenvolvimento desse trabalho no Brasil, tendo em vista que os mesmos são bons representantes de como se estabelece o uso das terras na porção semiárida nacional, por apresentarem algumas áreas reconhecidas como desertificadas, ao mesmo tempo em que são palco de intervenções desenvolvidas por Organizações Não-Governamentais (ONGs) e pelo Estado, cujo objetivo proposto é oferecer alternativas de convivência sustentável nessas terras.

\section{Procedimentos Metodológicos}

Para que fossem reconhecidas as diversas formas em que as terras são utilizadas nos municípios destacados e os seus efeitos na vegetação e nos solos, no período de 2009 a 2011 foram realizados diversos Trabalhos de Campo.

Em cada município, algumas áreas foram selecionadas para serem realizados procedimentos relacionados à análise da vegetação e qualidade 
dos solos. No primeiro caso, recorreu-se a execução de transectos em localidades com vegetação nativa presente, com o objetivo de se identificar como se encontrava a sua situação em ambiente considerado preservado ou que apresentava uso sustentável, em paralelo ao que estivesse degradado.

Foram feitos dois transectos para cada situação descrita acima, medindo cada parcela $50 \mathrm{~m}$ x 4m, método muito comum utilizado em estudos fitossociológicos em área de caatinga. Nesses transectos foram identificadas as espécies existentes de porte arbustivo e arbóreo, com circunferência na altura da base maior ou igual a $10 \mathrm{~cm}$; contabilizou-se a quantidade de indivíduos, os quais tiveram a sua altura medida e as Famílias às quais pertencem identificadas, a fim de se fazer uma comparação de resultados das diferentes situações. Destacamos que neste trabalho consideramos a densidade da cobertura vegetal e a variedade das espécies existentes como um elemento fundamental capaz de indicar até certo ponto a presença ou não de processos de desertificação.

A consideração anterior está baseada no fato de que a caatinga é um bioma onde domina originalmente uma vegetação de porte arbóreo, salvo algumas nuances dentro do complexo de paisagens passíveis de serem encontradas nessas terras. Além disso, outro ponto relevante em relação a esse bioma está relacionado ao fato de que, no conjunto das regiões de clima seco do mundo, este é um dos mais ricos em espécies.

Quanto ás Famílias dominantes, tal como ocorre em outras áreas de florestas sazonalmente secas, Leguminosae é a mais diversificada na caatinga, correspondendo a um terço do número total de espécies de plantas encontradas e um terço do número total de espécies endêmicas pesquisadas por Giulietti et al. (2002).

Paralelo a esse procedimento, nessas mesmas áreas, foram realizadas coletas de solos a $10 \mathrm{~cm}$ de profundidade para identificar, no Laboratório de Química e Fertilidade do Solo da Universidade Federal da Paraíba - UFPB/Campus II, como se comportaria a fertilidade natural diante das diferentes situações existentes.

Para analisarmos a condição da fertilidade dos solos coletados, destacamos os resultados encontrados em três elementos químicos, devido à elevada importância que os mesmos têm no que diz respeito a essa característica. Foram eles: fósforo, naturalmente deficiente em áreas de clima semiárido (SAMPAIO et al., 2005; SILVEIRA et al., 2006), cuja importância é fundamental para o desenvolvimento e produção da vegetação (JORGE, 1972a); potássio, atuante no crescimento, conformação 
e qualidade dos frutos (MESSIAS et al., 2008); e matéria orgânica, a qual melhora as propriedades físicas e químicas do solo e serve de fonte de elementos minerais para as plantas (JORGE, 1972b). Este último elemento também se caracteriza, normalmente, pela pequena presença em regiões de clima seco.

Em relação às análises e os resultados encontrados para a vegetação e os solos nos três municípios, tivemos a precaução de realizar os transectos e as coletas de solos em áreas cujas características de preservação e degradação estivessem dessa forma há pelo menos 20 anos, conforme relatos da população que habitava o entorno dessas terras. A adoção desse procedimento procura assim seguir o que a CCD (1995) define como degradação da terra, onde uma questão de fundamental importância relacionada à aquisição de dados diz respeito à série temporal em que estes foram adquiridos para acompanharmos a dinâmica do que vem acontecendo (SAMPAIO et al., 2005), evitando assim qualificarmos a paisagem como desertificada utilizando informações extraídas com base numa situação encontrada somente naquele momento.

Levando em consideração que, mesmo descartando a atuação humana, a tipologia das caatingas é muito heterogênea, em virtude da presença ou ausência de alguns atributos naturais, selecionamos áreas nos municípios analisados que apresentassem algumas similaridades. Isso ocorreu em relação à pluviosidade (médias abaixo de $700 \mathrm{~mm} / \mathrm{ano}$ ) e condições de relevo e altitude (planalto com declividades pouco a medianamente acentuadas e altitudes de 600 a $700 \mathrm{~m}$ ). Quanto aos solos presentes, estes foram um pouco mais heterogêneos em suas características.

\section{Resultados e Discussão}

\section{Município de Matureia}

O trabalho de campo ocorreu no período de 6 a 8 de novembro de 2009. Na oportunidade, foram observadas as ações desenvolvidas pelo Centro de Educação Popular e Formação Social (CEPFS), ONG que vem atuando desde 1979 nessa parte do Sertão da Paraíba e em outros municípios vizinhos, cujas ações junto aos pequenos agricultores estão relacionadas, de forma sintética, ao apoio técnico e educacional no que diz 
respeito ao desenvolvimento agrícola, na perspectiva da convivência com a seca.

Os trabalhos de desenvolvimento de tecnologias sociais e capacitação dos agricultores são realizados na sede dessa ONG, em propriedade situada na comunidade de Riacho das Moças, adquirida pelo CEPFS no início da década de 1990. Parte dessa propriedade, onde domina relevo com forte declividade, é destinada à preservação. No momento em que realizamos o trabalho de campo, essa área apresentava uma cobertura vegetal predominantemente arbórea, conforme pode ser observado na figura 2 , fruto de um processo de recuperação ambiental que passou a ocorrer quando da instalação da ONG nessa propriedade.

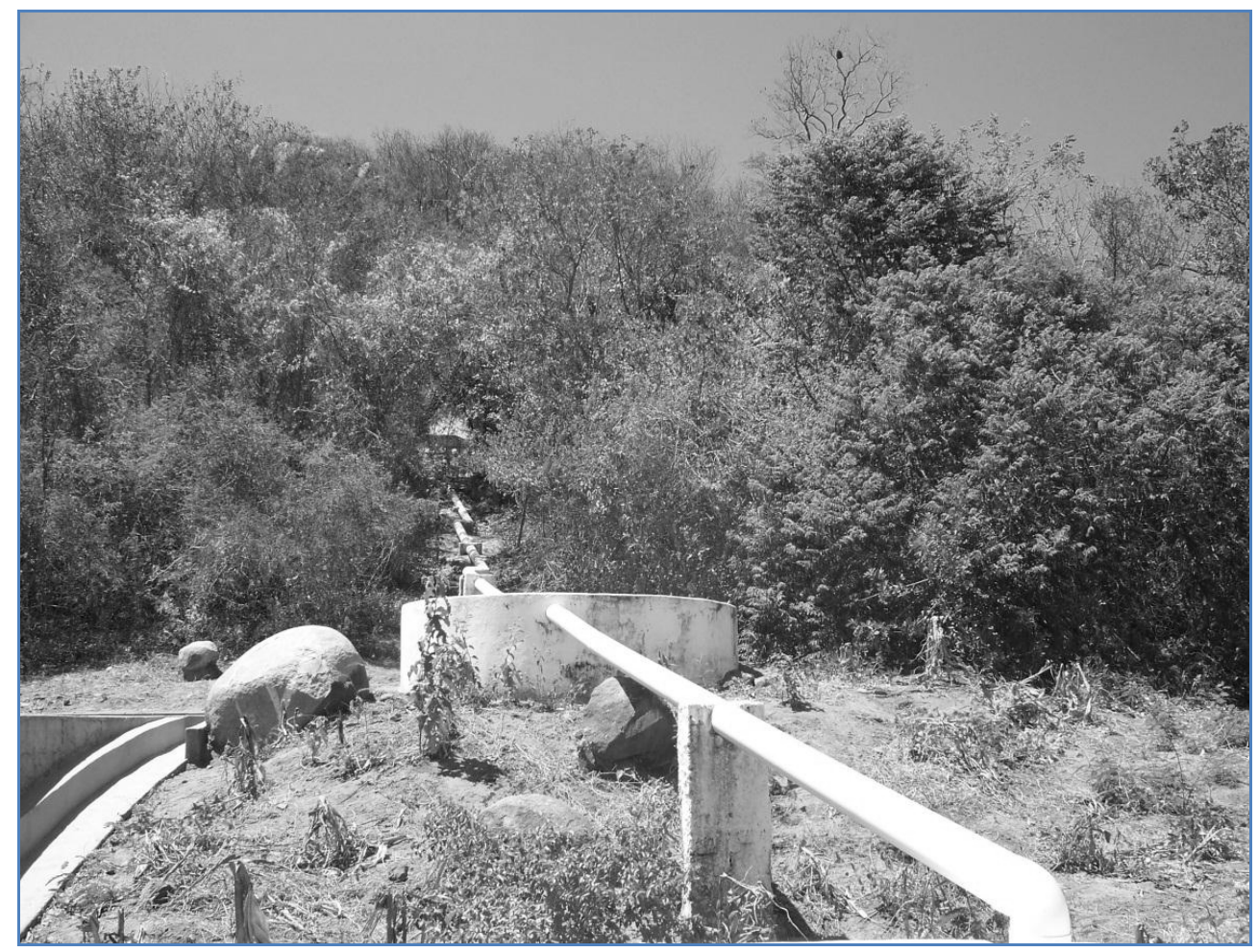

Figura 2. Aspecto da cobertura vegetal na área preservada no município de Matureia

Em situação oposta ao que ocorre nessa área pertencente ao CEPFS existe uma propriedade vizinha caracterizada pela forte degradação da 
vegetação e dos solos, aspecto bastante comum nessas terras, evidenciando como é a relação dominante entre os agricultores e esses recursos naturais na região. Nessa propriedade, além da rarefação da vegetação, os solos apresentavam-se com muitos ravinamentos, como pode ser observado na figura 3.

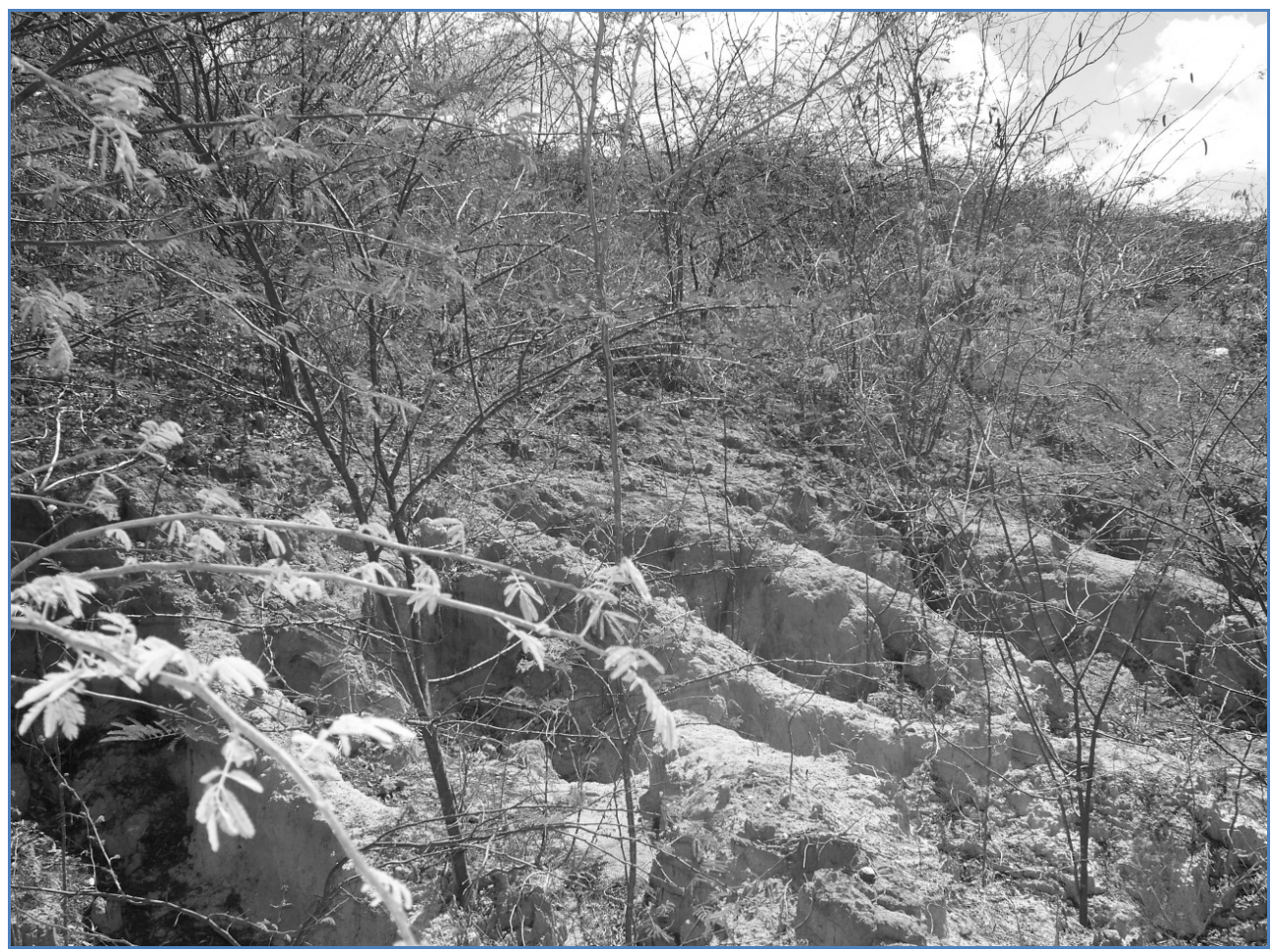

Figura 3. Ravinamentos na área degradada no município de Matureia

Os resultados encontrados para as análises da vegetação das duas localidades foram os apresentados nos Quadros 1 e 2.

\begin{tabular}{|c|c|c|c|}
\hline $\begin{array}{l}\text { Nome científico da } \\
\text { espécie }\end{array}$ & $\begin{array}{l}\text { Nome popular } \\
\text { da espécie }\end{array}$ & $\begin{array}{l}\text { Número de } \\
\text { indivíduos }\end{array}$ & Família \\
\hline $\begin{array}{c}\text { Combretum } \\
\text { leprosum }\end{array}$ & Mofumbo & 26 & Combretaceae \\
\hline
\end{tabular}




\begin{tabular}{|c|c|c|c|}
\hline $\begin{array}{c}\text { Anadenanthera } \\
\text { colubrina }\end{array}$ & Angico & 04 & Leguminosae \\
\hline $\begin{array}{c}\text { Piptadenia } \\
\text { stipulacea }\end{array}$ & Jurema-branca & 07 & Leguminosae \\
\hline $\begin{array}{l}\text { Bauhinia } \\
\text { cheilantha }\end{array}$ & Pata-de-vaca & 10 & Leguminosae \\
\hline Dioclea sp. & Olho-de-boi & 02 & Leguminosae \\
\hline Capparis flexuosa & Feijão-bravo & 13 & Capparaceae \\
\hline Croton sonderianus & Marmeleiro & 05 & Euphorbiaceae \\
\hline $\begin{array}{c}\text { Jatropha } \\
\text { mollissima }\end{array}$ & Pinhão-bravo & 01 & Euphorbiaceae \\
\hline $\begin{array}{l}\text { Helicteris } \\
\text { baruensis }\end{array}$ & - & 15 & Malvaceae \\
\hline Manihot glaziovii & Maniçoba & 07 & Euphorbiaceae \\
\hline Cereus jamacaru & Mandacaru & 03 & Cactaceae \\
\hline Bombax coreaceae & Imbiratanha & 01 & Bombacaceae \\
\hline $\begin{array}{c}\text { Myracroduon } \\
\text { urundeuva }\end{array}$ & Aroeira & 01 & Anacardiaceae \\
\hline $\begin{array}{l}\text { Commiphora } \\
\text { leptophloeos }\end{array}$ & Umburana & 01 & Burseraceae \\
\hline $\begin{array}{c}\text { Tabebuia } \\
\text { impetiginosa }\end{array}$ & Ipê-roxo & 01 & Bignoniaceae \\
\hline $\begin{array}{l}\text { Total de espécies: } \\
15\end{array}$ & - & $\begin{array}{l}\text { Total de } \\
\text { indivíduos: } 97\end{array}$ & Total de Famílias: 09 \\
\hline
\end{tabular}




\begin{tabular}{|l|l|}
\hline $\begin{array}{l}\text { Altura média das } \\
\text { espécies (m) }\end{array}$ & $\mathbf{7 , 1 0}$ \\
\hline
\end{tabular}

Quadro 1. Lista das espécies e Famílias encontradas em área com vegetação preservada (Matureia/PB)

\begin{tabular}{|l|l|c|l|}
\hline $\begin{array}{l}\text { Nome científico } \\
\text { da espécie }\end{array}$ & $\begin{array}{l}\text { Nome popular } \\
\text { da espécie }\end{array}$ & $\begin{array}{l}\text { Número de } \\
\text { indivíduos }\end{array}$ & Família \\
\hline $\begin{array}{l}\text { Mimosa } \\
\text { tenuiflora }\end{array}$ & Jurema-preta & 24 & Leguminosae \\
\hline $\begin{array}{l}\text { Piptadenia } \\
\text { stipulaceae }\end{array}$ & Jurema-branca & 05 & Leguminosae \\
\hline $\begin{array}{l}\text { Croton } \\
\text { sonderianus }\end{array}$ & Marmeleiro & 01 & Euphorbiaceae \\
\hline $\begin{array}{l}\text { Total de espécies: } \\
\text { 03 }\end{array}$ & - & $\begin{array}{l}\text { Total de } \\
\text { indivíduos: } 30\end{array}$ & $\begin{array}{l}\text { Total de Famílias: } \\
02\end{array}$ \\
\hline $\begin{array}{l}\text { Altura média das } \\
\text { espécies }\end{array}$ & \multicolumn{2}{|c|}{2,03} & \\
\hline
\end{tabular}

Quadro 2. Lista das espécies e Famílias encontradas em área com vegetação degradada (Matureia/PB)

Os resultados obtidos quanto à vegetação mostraram uma diferença marcante entre as duas situações analisadas. Neste caso, de um lado temos uma área com vegetação preservada, cuja composição, em quantidade e variedade, se aproximaria do que se espera encontrar numa área de caatinga onde não houve interferência humana direta ou se aproximaria desta situação. Por outro lado, na área degradada temos uma situação inversa, para a qual destacamos a pobreza de espécies, em quantidade e variedade, sobressaindo, em termos individuais, a presença da jurema-preta (M. tenuiflora), espécie pioneira de caatinga, representativa de um estágio inicial de sucessão ecológica. Dessa forma, fica evidenciado o quanto essa área foi alterada em relação às suas características originais.

Nessas propriedades também foram realizadas coletas de solos e, com base nas observações de campo, em BRASIL (1972) e Embrapa 
(2006), estes foram identificados nas duas situações como sendo do tipo Argissolo Vermelho-Amarelo Distrófico. Este tipo de solo é raso, apresentando textura de média a cascalhenta. Os resultados das análises de solos efetuadas nas amostras enviadas ao laboratório foram aquelas apresentadas no Quadro 3.

\begin{tabular}{|c|c|c|c|}
\hline Localidades & $\begin{array}{l}\text { Fósforo } \\
\left(\mathbf{m g} / \mathbf{d m}^{3}\right)\end{array}$ & $\begin{array}{l}\text { Potássio } \\
\left(\mathbf{m g} / \mathbf{d m}^{3}\right)\end{array}$ & $\begin{array}{l}\text { Matéria } \\
\text { Orgânica (g/kg) }\end{array}$ \\
\hline Preservada & 4,04 & 207,24 & 12,98 \\
\hline Degradada & 1,61 & 91,63 & 0,21 \\
\hline
\end{tabular}

Quadro 3. Análise química e de fertilidade dos solos coletados em Matureia

$\mathrm{Na}$ análise dos dados dos solos coletados, percebemos uma queda pronunciada dos elementos fósforo, potássio e matéria orgânica, quando comparamos a localidade preservada com a degradada. Partindo do princípio de que, originalmente, nas duas situações tínhamos padrões de vegetação e de características pedológicas no mínimo semelhantes, a diferença dos resultados encontrados mostra o quanto a localidade degradada foi alterada, tendo como causa a retirada excessiva da cobertura vegetal, expondo o solo a um intenso processo de modificação das suas características originais, relação essa que já era motivo de alerta desde a década de 1980, através das pesquisas desenvolvidas por Leprun (1981) no semiárido brasileiro.

Nessa área, até mesmo a presença de espécies pioneiras para o bioma caatinga, a exemplo da jurema preta ( $M$. tenuiflora), se caracteriza pelo número reduzido de indivíduos. Na literatura consultada, essa espécie está sempre relacionada ao processo de recuperação das áreas atingidas por algum tipo de degradação, porém neste trabalho não foram identificados processos de sucessão ecológica, demonstrando que essa área possui apenas indivíduos dessa espécie, os quais são mais adaptados que outras espécies da caatinga á uma condição de degradação severa.

Devido aos baixos níveis apresentados pelos elementos químicos presentes nos solos analisados, a reutilização agrícola dessa área seria muito difícil e onerosa, uma vez que a sua produtividade seria mínima ou mesmo inexistente. Fazendo uma relação dessa observação com a questão fundiária (domínio de pequenas propriedades) e o baixo poder financeiro 
dos pequenos agricultores dessa parte do Sertão da Paraíba para adquirirem insumos agrícolas capazes de reverter artificialmente esse quadro, a situação encontrada é muito preocupante, particularmente pelo fato de não ser um caso isolado na região.

No que diz respeito ao uso agrícola desenvolvido na propriedade do CEPFS, são cultivados diversos tipos de produtos alimentícios consorciados, a exemplo do milho e do feijão, enquanto em paralelo é praticada a fruticultura com espécies arbóreas (goiabeira e mangueira, principalmente) e arbustivas (acerola) e o cultivo de espécies forrageiras, tanto arbóreas (gliricídia) como arbustivas (palma-forrageira).

Essa diversidade dos produtos cultivados, em caso de uma seca mais severa, é capaz de garantir a safra de ao menos alguns destes gêneros, tendo em vista que as espécies cultivadas apresentam graus diferenciados de resistência ás estiagens. Além disso, essa diversidade agrícola também torna desnecessário o uso de agrotóxicos para combater possíveis pragas de insetos, já que este agroecossistema se assemelha, em sua variedade de espécies, ao que ocorreria numa caatinga preservada, onde a cadeia alimentar não foi alterada.

Para garantir ainda mais o sucesso da safra, é utilizada a irrigação por gotejamento nas plantas consumidos como alimento humano, através da adaptação de material plástico do tipo garrafa PET a esse fim, enquanto nas espécies consumidas como alimento pelo gado bovino e caprino, o uso da água é desnecessário, tendo em vista a sua capacidade maior de resistência à seca.

Dessa forma, através de técnicas simples e de baixo custo, a ONG em questão procura disseminar as experiências de convivência sustentável desenvolvidas em sua sede para as propriedades existentes nas terras semiáridas da região.

\section{Município de Soledade}

Em Soledade, o trabalho de campo ocorreu no período de 11 a 13 de novembro de 2009. Na ocasião, foram alvo mais intenso das nossas observações as comunidades rurais de Lajedo de Timbaúba e Malhada Vermelha, dominando a pecuária semi-extensiva para a produção de leite. Das duas comunidades analisadas, somente a primeira delas vem recebendo apoio e assistência técnica de uma ONG, denominada Programa 
de Aplicação de Tecnologia Apropriada às Comunidades (PATAC), o que acontece desde o início da década de 1990.

No semiárido, a atuação dessa ONG está voltada para a capacitação entre os jovens rurais em conhecimentos zootécnicos e gerenciais nas cadeias produtivas da caprinocultura e apicultura, apoio financeiro às economias populares de bairros e municípios com baixo Índice de Desenvolvimento Humano (IDH) - os Bancos Comunitários, além do apoio financeiro e técnico à produção agroecológica, beneficiamento de frutas nativas e desenvolvimento de sistemas de captação de água para a produção agropecuária.

Os mesmos procedimentos tomados quanto à realização de transectos para análise da vegetação em Matureia, também foram executados em Soledade. Os resultados obtidos são os que constam nos Quadros 4 e 5.

\begin{tabular}{|l|l|c|l|}
\hline $\begin{array}{l}\text { Nome científico da } \\
\text { espécie }\end{array}$ & $\begin{array}{l}\text { Nome popular } \\
\text { da espécie }\end{array}$ & $\begin{array}{l}\text { Número de } \\
\text { indivíduos }\end{array}$ & Família \\
\hline Croton sonderianus & Marmeleiro & 47 & Euphorbiaceae \\
\hline Manihot glaziovii & Maniçoba & 14 & Euphorbiaceae \\
\hline $\begin{array}{l}\text { Jatropha } \\
\text { mollissima }\end{array}$ & Pinhão-bravo & 01 & Euphorbiaceae \\
\hline Bombax coreaceae & Imbiratanha & 04 & Bombacaceae \\
\hline $\begin{array}{l}\text { Myracroduon } \\
\text { urundeuva }\end{array}$ & Aroeira & 04 & Anacardiaceae \\
\hline $\begin{array}{l}\text { Caesalpinia } \\
\text { pyramidalis }\end{array}$ & Catingueira & 03 & Leguminosae \\
\hline $\begin{array}{l}\text { Anadenanthera } \\
\text { colubrina }\end{array}$ & Angico & 02 & Leguminosae \\
\hline $\begin{array}{l}\text { Piptadenia } \\
\text { stipulacea }\end{array}$ & Jurema-branca & 01 & Leguminosae \\
\hline
\end{tabular}




\begin{tabular}{|l|l|c|l|}
\hline $\begin{array}{l}\text { Pilosocereus } \\
\text { piauiensis }\end{array}$ & Facheiro & 03 & Cactaceae \\
\hline $\begin{array}{l}\text { Aspidosperma } \\
\text { pyrifolium }\end{array}$ & Pereiro & 03 & Apocyanceae \\
\hline $\begin{array}{l}\text { Commiphora } \\
\text { leptophloeos }\end{array}$ & Umburana & 01 & Burseraceae \\
\hline $\begin{array}{l}\text { Total de espécies: } \\
11\end{array}$ & - & $\begin{array}{c}\text { Total de } \\
\text { indivíduos: } 83\end{array}$ & Total de Famílias: 07 \\
\hline $\begin{array}{l}\text { Altura média das } \\
\text { espécies (m) }\end{array}$ & & \multicolumn{3}{|c|}{} \\
\hline
\end{tabular}

Quadro 4. Lista das espécies e Famílias encontradas na área Lajedo de Timbaúba Soledade/PB (local com uso sustentável)

\begin{tabular}{|l|l|c|l|}
\hline $\begin{array}{l}\text { Nome científico } \\
\text { da espécie }\end{array}$ & $\begin{array}{l}\text { Nome popular } \\
\text { da espécie }\end{array}$ & $\begin{array}{l}\text { Número de } \\
\text { indivíduos }\end{array}$ & Família \\
\hline $\begin{array}{l}\text { Croton } \\
\text { sonderianus }\end{array}$ & Marmeleiro & 43 & Euphorbiaceae \\
\hline $\begin{array}{l}\text { Croton campestris } \\
\text { Jatropha } \\
\text { mollissima }\end{array}$ & Velame & 03 & Euphorbiaceae \\
\hline $\begin{array}{l}\text { Caesalpinia } \\
\text { pyramidalis }\end{array}$ & Catingueira & 01 & Euphorbiaceae \\
\hline $\begin{array}{l}\text { Piptadenia } \\
\text { stipulaceae }\end{array}$ & Jurema-branca & 01 & Leguminosae \\
\hline $\begin{array}{l}\text { Aspidosperma } \\
\text { pyrifolium }\end{array}$ & Pereiro & 04 & Apocynaceae \\
\hline Pilosocereus & Xique-xique & 02 & Cactaceae \\
\hline
\end{tabular}




\begin{tabular}{|l|c|c|c|}
\hline $\begin{array}{c}\text { gounellei } \\
\text { Total de espécies: } \\
07\end{array}$ & - & $\begin{array}{c}\text { Total de } \\
\text { indivíduos: } 80\end{array}$ & Total de Famílias: 04 \\
\hline $\begin{array}{l}\text { Altura média das } \\
\text { espécies (m) }\end{array}$ & \multicolumn{2}{|c|}{1,73} & \\
\hline
\end{tabular}

Quadro 5. Lista das espécies e Famílias encontradas na área de Malhada Vermelha Soledade/PB (local degradado)

Os resultados encontrados mostram uma maior riqueza tanto em diversidade como em abundância das espécies vegetais para Lajedo de Timbaúba, em comparação com Malhada Vermelha, indicando um maior grau de conservação para a primeira comunidade, aspecto facilmente perceptível nas figuras 4 e 5, a seguir.

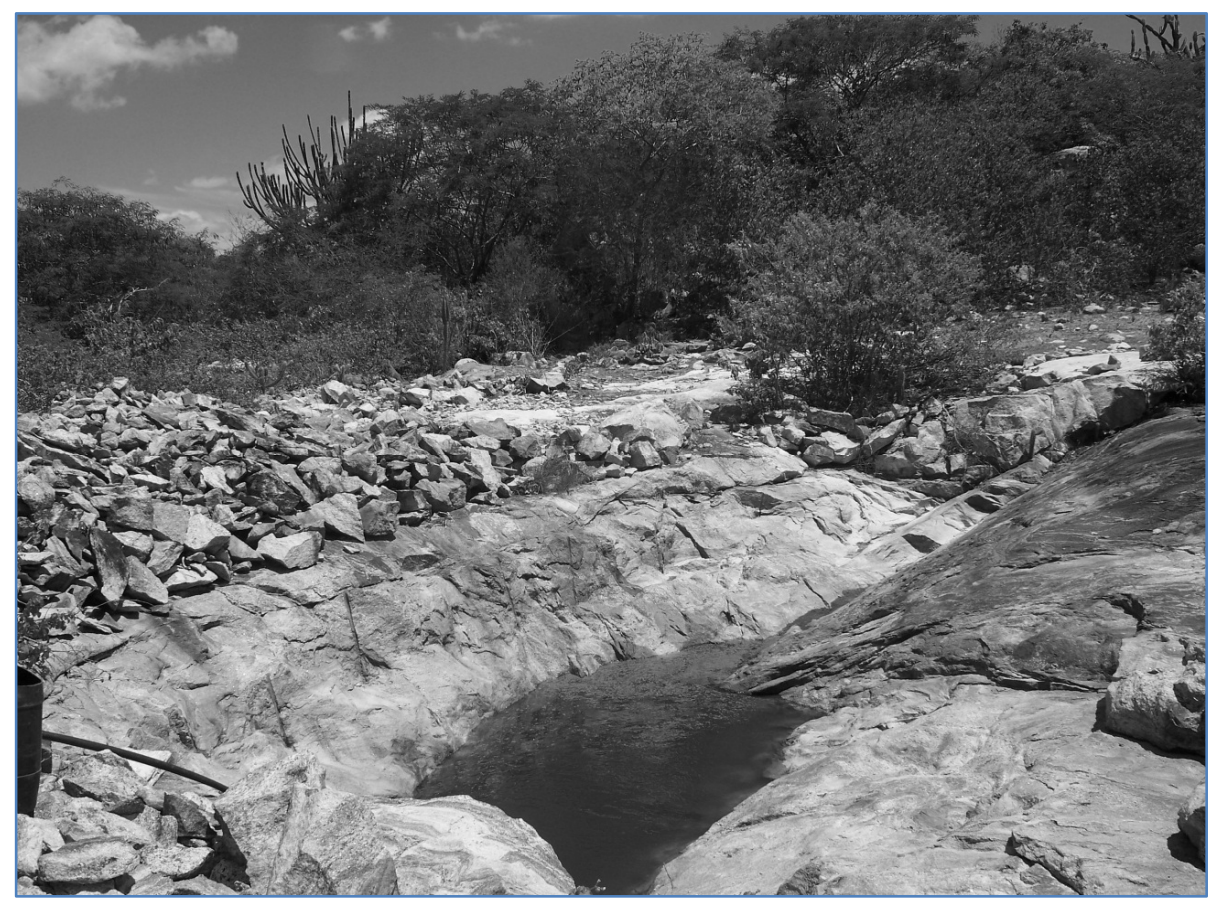

Figura 4. Aspecto da cobertura vegetal na comunidade Lajedo de Timbaúba (local com uso sustentável) 


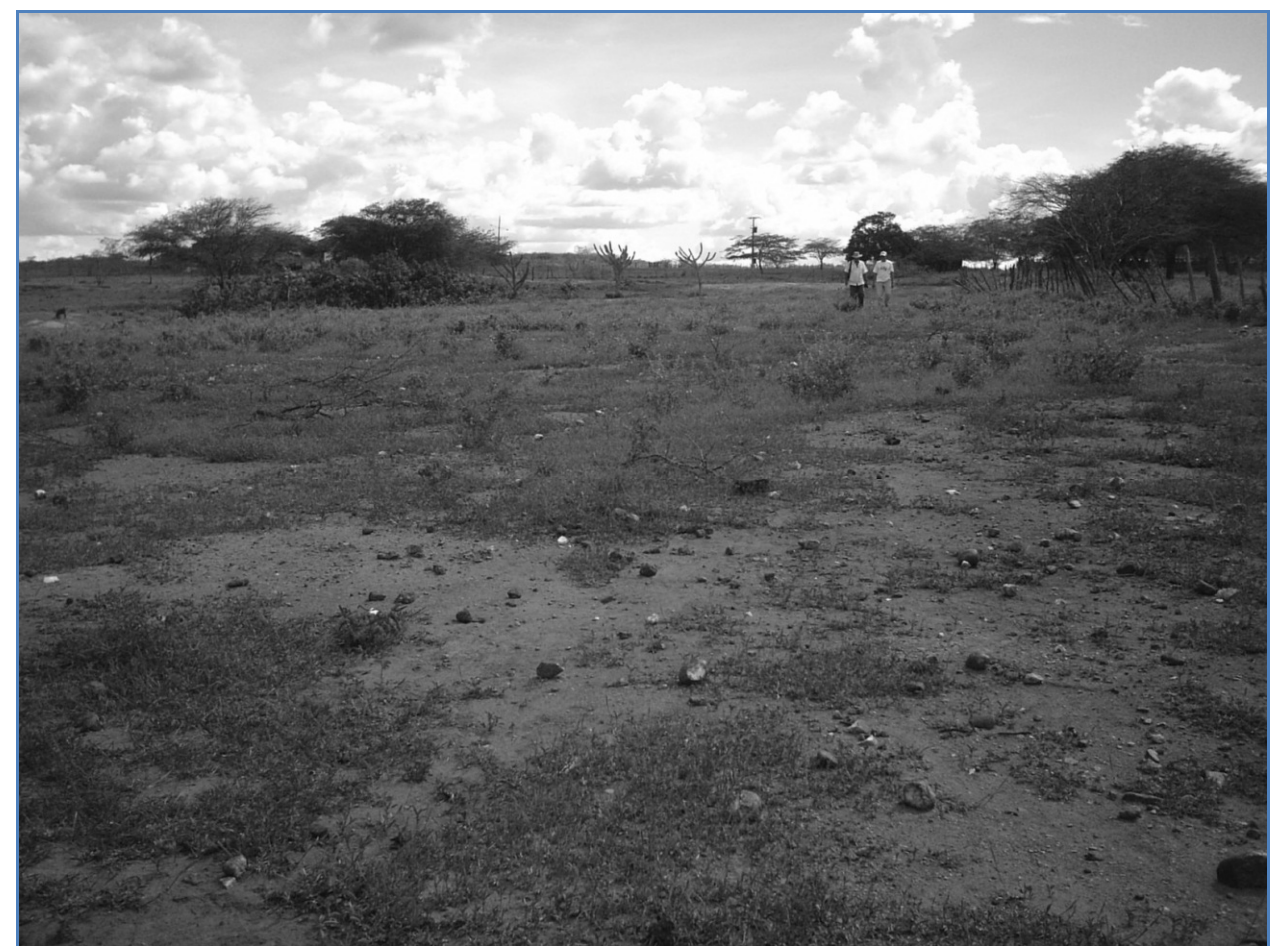

Figura 5. Aspecto da cobertura vegetal na comunidade Malhada Vermelha (local degradado)

Destacamos também que em Malhada Vermelha chamou atenção a grande quantidade de indivíduos de marmeleiro ( $C$. sonderianus), uma das espécies existentes na caatinga indicadora de uma sucessão ecológica em estágio inicial, sendo muito comum a sua dominância, neste bioma, em áreas que sofreram desmatamentos constantes. Quanto aos solos coletados para análise de fertilidade, com base nas observações em campo, em BRASIL (1972) e Embrapa (2006), estes foram identificados como sendo do tipo Neossolo Regolítico Eutrófico. Os resultados para análise de fertilidade dos solos dessas localidades foram os apontados no Quadro 6. 


\begin{tabular}{|c|c|c|c|}
\hline Localidades & $\begin{array}{c}\text { Fósforo } \\
\left(\mathbf{m g} / \mathbf{d m}^{\mathbf{3}}\right)\end{array}$ & $\begin{array}{c}\text { Potássio } \\
\left(\mathbf{m g} / \mathbf{d m}^{\mathbf{3}}\right)\end{array}$ & $\begin{array}{c}\text { Matéria } \\
\text { Orgânica }(\mathbf{g} / \mathbf{k g})\end{array}$ \\
\hline Preservada & 15,86 & 270,24 & 8,97 \\
\hline Degradada & 9,46 & 180,86 & 7,28 \\
\hline
\end{tabular}

Quadro 6. Análise química e de fertilidade dos solos coletados em Lajedo da Timbaúba Soledade/PB (local preservado) e Malhada Vermelha (local degradado)

Os resultados obtidos em Soledade, nas duas localidades amostradas, são parcialmente semelhantes aos que foram identificados em Matureia, uma vez que, em ambos os casos, ocorre uma diferença visível entre os valores dos elementos analisados em condições de uso sustentável e de degradação. Entretanto, a proximidade da quantidade de fósforo, potássio e matéria orgânica é muito maior nos solos coletados em Soledade, uma vez que estes apresentam uso mais regular, o que acarreta uma maior perda dos elementos analisados, particularmente o último citado. Por outro lado, tanto na localidade com uso sustentável como na degradada, comparando essas situações nos dois municípios, Soledade apresenta valores maiores de fósforo e potássio que os encontrados em Matureia.

Levando em consideração que em nenhuma das localidades analisadas nesses municípios ocorreu adição artificial desses elementos químicos, a resposta para essa diferença está baseada no fato de serem solos diferentes: Argissolo Vermelho-Amarelo Distrófico em Matureia e Neossolo Regolítico Eutrófico em Soledade, o que lhes confere diversas características originais que os distinguem um do outro.

Nos solos do tipo Argissolo Vermelho-Amarelo Distrófico coletados em Matureia, a fertilidade é afetada pelo fato de estarem localizados em áreas com relevo movimentado e encostas pouco longas, onde a erosão laminar é severa, mesmo que estas apresentem cobertura vegetal (BRASIL, 1972; EMBRAPA, 2006). Nos solos do tipo Neossolo Regolítico Eutrófico, o fósforo apresenta-se normalmente em níveis baixos. Entretanto, em situações em que exista forte proximidade com a rocha ou horizonte com mais matéria orgânica, esses valores tendem a aumentar substancialmente. Nas localidades de Soledade onde foram efetuadas as coletas desse tipo de solo, a rocha cristalina aflora facilmente à superfície, o que justifica os valores encontrados para esse elemento. 
Em relação ao potássio, como as rochas que originam esse último tipo de solo são muito ricas em feldspato potássico, isso explica a abundância do mesmo nas amostras coletadas (BRASIL, 1972). Por essas razões, esse tipo de solo, nas coletas realizadas em Soledade, é classificado como eutrófico.

Sobre os resultados antagônicos encontrados nas duas comunidades quanto à análise da vegetação e dos solos, percebe-se facilmente que há uma relação positiva no que diz respeito às ações empreendias pelo PATAC em Lajedo de Timbaúba, ocorrendo o contrário em Malhada Vermelha onde, apesar de também dominar a pecuária leiteira, esta ocorre sem nenhum tipo de assistência técnica, quer seja por ONG, quer seja pelo Estado.

Em Lajedo de Timbaúba, a atuação do PATAC consiste em grande parte na disseminação do uso do rodízio das áreas de pasto nativo, a fim de que estes possam continuar a ser utilizados sem que haja o seu desgaste, o que tem se mostrado positivo para a vegetação, os solos e, consequentemente, para a comunidade em questão.

Dessa forma, observamos que em situações fundiárias semelhantes (pequenas propriedades), o nível de conservaçã̃o dos elementos analisados é completamente diferente, tendo em vista a disseminação de uma melhor adequação técnica numa comunidade em relação à outra.

\section{Município de São João do Tigre}

Nesse município, o trabalho de campo ocorreu no período de 20 a 21 de setembro de 2010. São João do Tigre apresenta duas particularidades em relação aos outros municípios pesquisados nesse projeto. A primeira delas é de que, até aquele momento, não existia nenhuma ONG atuando em suas terras. A segunda particularidade é que grande parte do seu território está inserido numa Unidade de Conservação Estadual, a Área de Proteção Ambiental (APA) das Onças. Dessa forma, as análises realizadas nesse trabalho foram baseadas nas ações do Governo do Estado da Paraíba enquanto gestor dessa APA, através da Superintendência de Administração do Meio Ambiente (SUDEMA), órgão responsável pela fiscalização e controle das atividades desenvolvidas nessa área.

A APA das Onças foi criada no ano de 2002, passando a ser, a partir de então, a maior unidade de conservação da Paraíba, com uma área de 36.000 ha. Este aspecto quantitativo se torna ainda mais relevante 
quando sabemos que a presença de áreas protegidas no bioma caatinga é pouco significativa no estado, correspondendo a apenas $1,0 \%$ do seu território.

A título de comparação entre o tipo de vegetação encontrada e as consequências da sua retirada para a fertilidade dos solos, tal como nos casos anteriores, foram feitos quatro transectos dentro da APA, sendo dois para cada localidade, uma preservada e outra degradada.

A localidade preservada encontra-se em relevo declivoso, com forte cobertura vegetal arbórea e solo identificado com base nas observações de campo, em BRASIL (1972) e Embrapa (2006), como sendo do tipo Neossolo Regolítico Distrófico. Até o momento de realização deste trabalho, o único tipo de uso econômico identificado nessa área foi a pecuária semi-extensiva, ainda que de forma incipiente.

A localidade degradada, por sua vez, apresenta relevo plano, com pequena cobertura vegetal do tipo arbustiva e espaçada. O tipo de solo identificado é o mesmo encontrado anteriormente. Quanto ao uso, também domina a pecuária semi-extensiva, embora com maior intensidade que na localidade preservada. Os resultados encontrados para a vegetação foram os apresentados nos Quadros 7 e 8.

\begin{tabular}{|l|l|c|l|}
\hline $\begin{array}{l}\text { Nome científico da } \\
\text { espécie }\end{array}$ & $\begin{array}{l}\text { Nome popular } \\
\text { da espécie }\end{array}$ & $\begin{array}{l}\text { Número de } \\
\text { indivíduos }\end{array}$ & Família \\
\hline Ximenia americana & Ameixa & 10 & Olacaceae \\
\hline $\begin{array}{l}\text { Tabebuia } \\
\text { impetiginosa }\end{array}$ & Ipê-roxo & 08 & Bignoniaceae \\
\hline $\begin{array}{l}\text { Anadenanthera } \\
\text { colubrina }\end{array}$ & Angico & 06 & Leguminosae \\
\hline $\begin{array}{l}\text { Caesalpinia } \\
\text { pyramidalis }\end{array}$ & Catingueira & 05 & Leguminosae \\
\hline $\begin{array}{l}\text { Caesalpinia ferrea } \\
\text { Piptadenia } \\
\text { stipulaceae }\end{array}$ & Pau-ferro & 04 & Leguminosae \\
\hline
\end{tabular}




\begin{tabular}{|c|c|c|c|}
\hline Bauhinia cheilantha & Pata-de-vaca & 02 & Leguminosae \\
\hline $\begin{array}{l}\text { Enterolobium } \\
\text { contortisiliquum }\end{array}$ & Tambor & 01 & Leguminosae \\
\hline Ceiba glaziovii & Barriguda & 03 & Bombacaceae \\
\hline Syagrus cearensis & Catolé & 04 & Arecaceae \\
\hline Croton sonderianus & Marmeleiro & 02 & Euphorbiaceae \\
\hline $\begin{array}{c}\text { Total de espécies: } \\
11\end{array}$ & - & $\begin{array}{c}\text { Total de } \\
\text { indivíduos: } 48\end{array}$ & $\begin{array}{c}\text { Total de Famílias: } \\
06\end{array}$ \\
\hline $\begin{array}{l}\text { Altura média das } \\
\text { espécies }(\mathrm{m})\end{array}$ & \multicolumn{3}{|c|}{8,20} \\
\hline
\end{tabular}

Quadro 7. Lista das espécies e Famílias encontradas em São João do Tigre - APA das Onças/PB (local preservado)

\begin{tabular}{|l|l|c|l|}
\hline $\begin{array}{l}\text { Nome científico } \\
\text { da espécie }\end{array}$ & $\begin{array}{l}\text { Nome } \\
\text { popular da } \\
\text { espécie }\end{array}$ & $\begin{array}{l}\text { Número de } \\
\text { indivíduos }\end{array}$ & Família \\
\hline Mimosa tenuiflora & Jurema-preta & 20 & Leguminosae \\
\hline $\begin{array}{l}\text { Aspidosperma } \\
\text { pyrifolium }\end{array}$ & Pereiro & 08 & Apocynaceae \\
\hline $\begin{array}{l}\text { Pilosocereus } \\
\text { gounellei }\end{array}$ & Xique-xique & 04 & Cactaceae \\
\hline $\begin{array}{l}\text { Plisocereus } \\
\text { piauiensis }\end{array}$ & Facheiro & 02 & Cactaceae \\
\hline $\begin{array}{l}\text { Jatropha } \\
\text { mollissima }\end{array}$ & Pinhão-bravo & 04 & Euphorbiaceae \\
\hline $\begin{array}{l}\text { Total de espécies: } \\
05\end{array}$ & - & $\begin{array}{c}\text { Total de } \\
\text { indivíduos: } 38\end{array}$ & Total de Famílias: 04 \\
\hline
\end{tabular}




\begin{tabular}{|l|l|}
\hline $\begin{array}{l}\text { Altura média das } \\
\text { espécies (m) }\end{array}$ & 2,10 \\
\hline
\end{tabular}

Quadro 8. Lista das espécies e Famílias encontradas em São João do Tigre - APA das Onças/PB (local degradado)

Tal como nas situações anteriores, chama atenção a diferença de cobertura vegetal existente nas duas localidades. Além disso, destaca-se na localidade degradada a presença elevada de jurema-preta ( $M$. tenuiflora), demonstrando o estágio inicial de sucessão ecológica que está ocorrendo. Esses aspectos são facilmente visíveis nas paisagens dessas duas localidades, como mostram as figuras 6 e 7, a seguir.

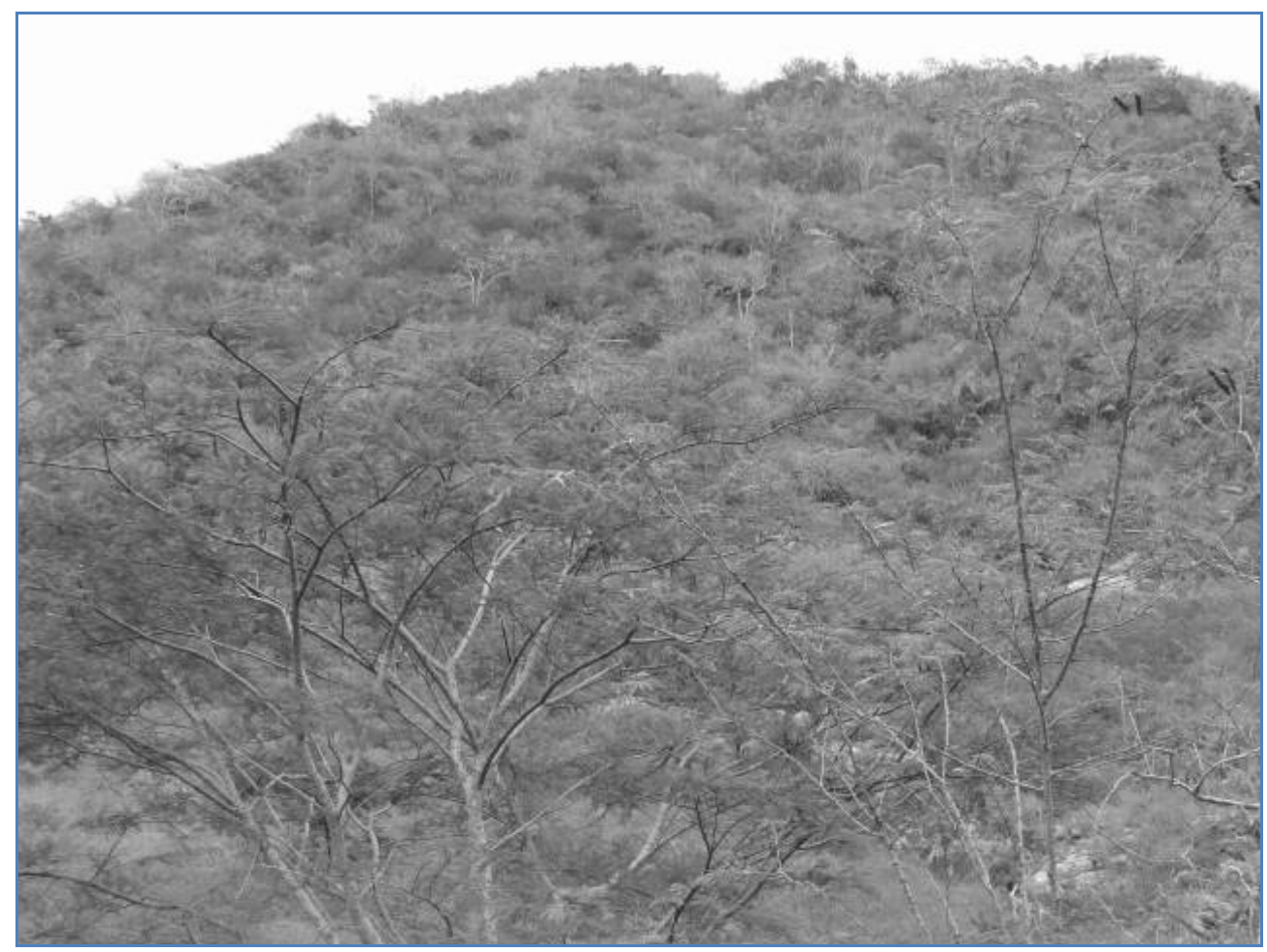

Figura 6. Aspecto da cobertura vegetal na área preservada da APA das Onças 


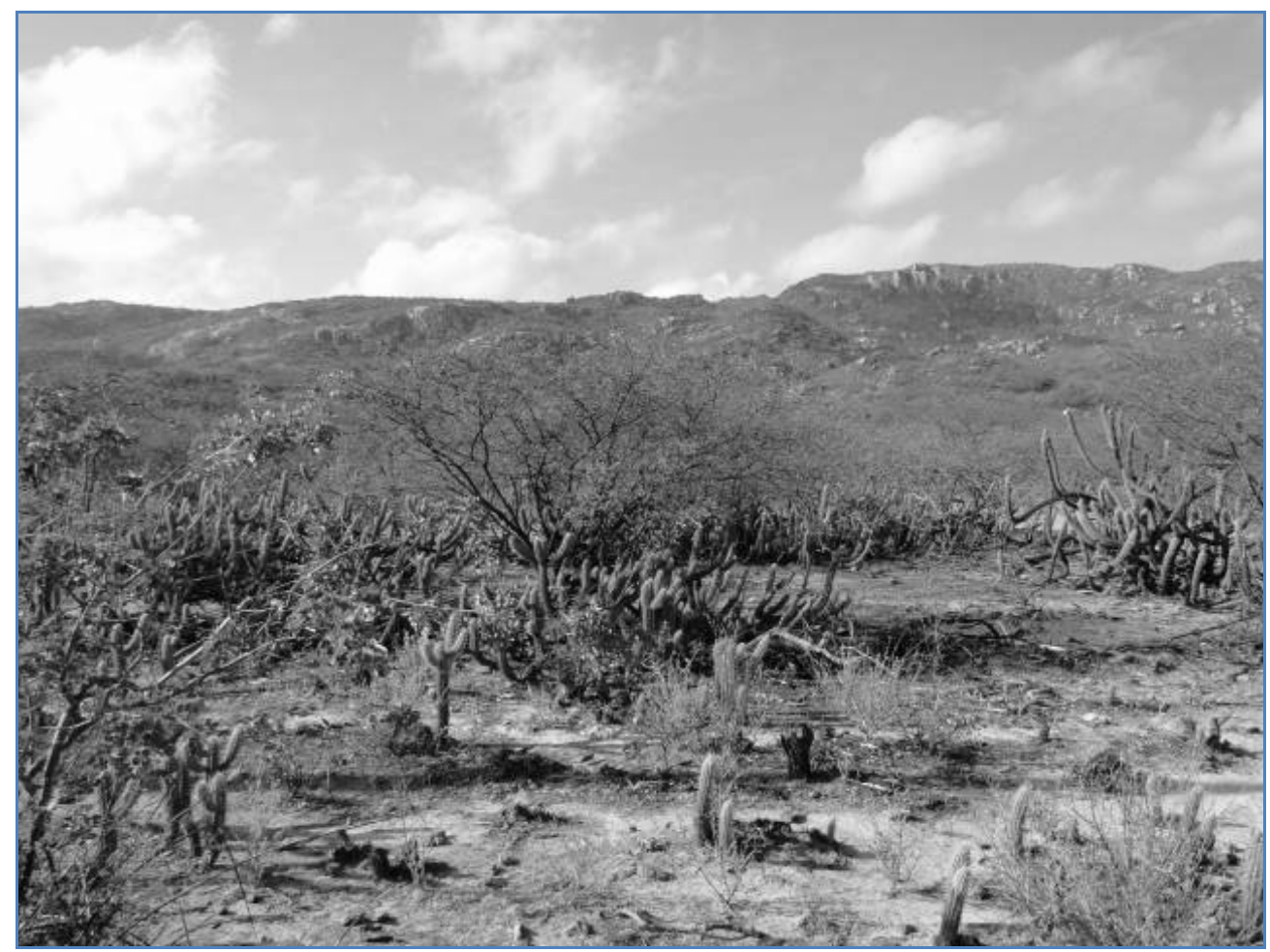

Figura 7. Aspecto da cobertura vegetal na área degradada da APA das Onças

Em relação à fertilidade dos solos nessas localidades, os resultados encontrados estão apontados no Quadro 9.

\begin{tabular}{|c|c|c|c|}
\hline Localidades & $\begin{array}{l}\text { Fósforo } \\
\left(\mathbf{m g} / \mathbf{d m}^{3}\right)\end{array}$ & $\begin{array}{l}\text { Potássio } \\
\left(\mathbf{m g} / \mathbf{d m}^{3}\right)\end{array}$ & $\begin{array}{l}\text { Matéria } \\
\text { Orgânica (g/kg) }\end{array}$ \\
\hline Preservada & 48,54 & 307,98 & 17,84 \\
\hline Degradada & 15,09 & 52,06 & 2,85 \\
\hline
\end{tabular}

Quadro 9. Análise química e de fertilidade dos solos coletados em São João do Tigre APA das Onças/PB

Seguindo a regra para o que foi observado nas outras áreas dos municípios anteriormente analisados, os resultados mostraram uma estreita 
relação entre a presença de vegetação e a quantidade de fósforo, potássio e matéria orgânica, os quais diminuem de forma expressiva quando o local se encontra degradado.

Comparando os resultados encontrados para os locais analisados nesse município em relação a Soledade, onde as amostras de solos, embora com variedades distintas, são do mesmo tipo (Neossolo Regolítico), observamos que, no geral, a situação nos locais considerados preservado e degradado em São João do Tigre é melhor, o que é possivelmente explicado pelo uso menos intenso das terras nesse último município, onde foram realizadas as coletas. A exceção fica por conta dos valores encontrados para o potássio, nos locais preservados e degradados dos dois municípios, sendo que Soledade apresenta números superiores. Isto se deve ao fato da variedade de Neossolo Regolítico existente nos dois municípios ser diferente, ou seja, distrófico em São João do Tigre e eutrófico em Soledade.

A característica pedológica anteriormente destacada para a área de São João do Tigre, onde ocorreu a coleta de solos, é resultante da presença de maior pluviosidade na localidade serrana deste município, fazendo com que haja aumento da lixiviação das bases encontradas, acarretando diminuição das percentagens de feldspato potássico disponíveis.

Reiteramos que os resultados das análises nesses locais de São João do Tigre, se por um lado reforçam ainda mais a importância da preservação da vegetação enquanto elemento fundamental na preservação da fertilidade dos solos, por outro também nos encaminha a refletir sobre uma situação que, se já era preocupante ao tratar do bioma caatinga na Paraíba fora das áreas sob proteção ambiental, torna-se ainda mais grave quando se constata que, mesmo nas áreas protegidas por lei, como é o caso da APA das Onças, ocorrem casos semelhantes.

Em relação à vegetação, comparando os resultados encontrados nas áreas analisadas nos três municípios, verificou-se maior número e variedade de Famílias e espécies onde existem melhores condições de preservação, o que também foi identificado em outros trabalhos consultados realizados no bioma caatinga (LUNA, 1998; PEREIRA et al., 2003; ANDRADE et al., 2005).

Quanto às Famílias dominantes, Anacardiaceae, Burseraceae e Capparidaceae são encontradas apenas nas localidades mais preservadas de Matureia e Soledade, o que, possivelmente, está relacionado ao fato dos seus representantes não suportarem condições de forte degradação, tal 
como foi observado por Andrade et al. (2005) no município de São João do Cariri (Paraíba).

No local preservado analisado em São João do Tigre, tivemos a ocorrência de representantes das Famílias Olacaceae e Aracaceae, o que deve ser resultante não apenas do efeito do nível de preservação da área, mas também da presença de uma maior umidade média, quando comparada com a situação dos outros dois municípios, em virtude das altitudes mais elevadas aí registradas (acima de $700 \mathrm{~m}$ ), fator esse que torna os níveis de evapotranspiração mais baixos devido ao domínio de temperaturas médias menos elevadas, beneficiando diretamente algumas espécies mais exigentes em água, como é o caso dos representantes dessas Famílias.

Quanto à recuperação espontânea das áreas degradadas analisadas nesse trabalho, embora seja uma situação possível de ocorrer, uma das dificuldades encontradas está relacionada ao uso contínuo e geralmente predatório dessas terras, submetidas constantemente a queimadas para aproveitamento agrícola e formação de pastagem, prática que, se em princípio confere aos solos o retorno de parte da fertilidade perdida, ao adicionar uma série de elementos antes contidos diretamente na vegetação, com a sua continuidade acaba promovendo a queda da produtividade.

Esse uso tradicional, se no passado era mais rotativo, devido ao tamanho maior das propriedades, o que permitia maior período de pousio para as parcelas utilizadas, beneficiando os ecossistemas manejados, tornou-se quase impossível de continuar a ser realizado, devido a séculos de repartição das propriedades por herança entre os familiares, fazendo com que a pressão sobre este meio ficasse cada vez mais elevada, acarretando numa maior intensificação do uso dos solos e da vegetação nativa (SOUZA, 2008).

Também contribuindo fortemente para dificultar ainda mais a recuperação espontânea dessas áreas, temos a rarefação extrema da fauna silvestre, quer seja pela caça ou pelo fogo (direta e indiretamente), a qual era responsável pela dispersão e reprodução das espécies vegetais (SA et al., 1994).

Em relação às experiências desenvolvidas na propriedade do CEPFS, em Matureia, e pelo PATAC, em Soledade, essas funcionam como uma "vitrine" para incentivar os agricultores dessa parte da Paraíba e das suas vizinhanças a praticarem as mesmas técnicas empregadas por essas ONGs e, assim, poderem viver de forma sustentável no semiárido, evitando o processo de desertificação. 
O papel dessas e de outras ONGs, cuja presença no semiárido brasileiro ocorre de forma marcante, particularmente a partir dos anos 1980 , tem sido fundamental para que diversas comunidades venham estabelecendo a construção de outra relação com esse espaço, "[...] pressupondo novas formas de aprender a lidar com esse ambiente, na busca de alcançar e transformar todos os setores da vida [...]" (CARVALHO, 2004:22).

Além disso, a importância desses atores nessa região é ainda mais fundamental quando percebemos que a atuação do Estado, embora tenha melhorado em tempos mais recentes, apresenta uma longa história de falhas ou mesmo ausência no que diz respeito ao suprimento das necessidades de grande parte da população que habita essas terras, passando as ONGs a ocuparem parte dessa lacuna entreaberta.

Reconhecemos, entretanto, que, embora a atuação do CEPFS e do PATAC tenha obtido resultados muito relevantes, mostrando que é possível a convivência no semiárido brasileiro a partir de uma intervenção sustentável, as respostas obtidas são muito pontuais, devendo haver ainda um grande esforço por parte dos órgãos não governamentais e pela sociedade civil organizada para que se obtenha uma maior disseminação de práticas agropecuárias adequadas aos ambientes inseridos nas áreas com risco de desertificação.

O caso da APA das Onças serve de exemplo para percebermos que a ação do Estado na Paraíba tem se caracterizado também pela omissão das suas funções ambientais, uma vez que não atua eficazmente enquanto fiscalizador do cumprimento das leis em áreas oficialmente protegidas, o que vem acarretando em algumas partes dessa unidade de conservação degradação da vegetação e dos solos. Ressaltamos ainda que nessa região o Estado praticamente não tem desenvolvido com a população local medidas educacionais que as preparem para lidar de forma sustentável com os recursos naturais, incluindo-se aí a viabilização de alternativas capazes de levar os habitantes a outro patamar econômico, social e ambiental, a exemplo do ecoturismo que poderia ser desenvolvido na APA das Onças.

Quanto à atuação do Estado em nível federal no combate ao processo de desertificação, a despeito da existência do Programa de Ação Nacional de Combate à Desertificação e Mitigação dos Efeitos da Seca/PAN Brasil, o qual se compromete a desenvolver medidas com esse objetivo desde o início dessa década (BRASIL, 2004), nenhum tipo de ação dessa natureza foi identificado nas áreas degradadas analisadas nesse trabalho ou em outras existentes em suas proximidades. 


\section{Considerações Finais}

A questão ambiental, se no passado foi relegada a uma condição periférica ou mesmo esteve completamente esquecida no conjunto das ações desenvolvidas, é motivo de uma preocupação cada vez mais crescente, fazendo com que toda a sociedade incorpore, ao menos em tese, o paradigma da sustentabilidade. As regiões pesquisadas na Paraíba oferecem diversos exemplos de como as ONGs e o Estado tem atuado nesses territórios, quer seja através do desenvolvimento de ações diretas, quer seja pela omissão.

Entre as semelhanças detectadas nas ações dos agentes analisados nas áreas pesquisadas, observamos por parte das ONGs a preocupação em procurar formas menos degradantes de intervenção, tanto do ponto vista social como ambiental, ao mesmo tempo em que buscam resultados econômicos que ofereçam uma maior satisfação às necessidades básicas das populações envolvidas no processo. Neste caso, os resultados que expusemos podem ser considerados positivos.

No caso das ONGs destacadas neste trabalho, o esforço é para criar uma situação de convivência com as secas, assim como o respeito aos limites dos recursos naturais disponíveis, questões que durante muito tempo foram esquecidas por parte da população e também pelo Estado, resultando numa série de malefícios para diversas regiões periféricas do mundo, inclusive as que foram abordadas nesse trabalho. Por outro lado, em relação ao Estado, observamos que os efeitos negativos ocorrem quando este não cumpre o que ele próprio estabeleceu em forma de lei e também enquanto agente executor de uma série de políticas públicas, como as que se encontram no Programa de Ação Nacional de Combate à Desertificação e Mitigação dos Efeitos das Secas/PAN-Brasil.

Entendemos assim que diversas das ações positivas observadas podem ser reproduzidas em outras áreas susceptíveis à desertificação do Brasil, assim como nas ASDs que fizeram parte deste projeto de pesquisa, em Portugal e Cabo Verde, desde que sejam identificadas e respeitadas as especificidades naturais onde esse tipo de degradação pode ocorrer, bem como as questões sociais que caracterizam essas áreas, o que requer um aprofundamento do reconhecimento das singularidades e das adaptações que as possíveis intervenções têm de sofrer para serem implantadas e obterem sucesso. 


\section{USO DA VEGETAÇÃO E DOS SOLOS EM ÁREAS SUSCEPTÍVEIS À DESERTIFICAÇÃO NA PARAÍBA/BRASIL}

Resumo: A desertificação é um tipo de degradação que ocorre nas zonas de clima seco do mundo, sendo resultante principalmente de algumas ações desenvolvidas para o aproveitamento econômico das terras nessas áreas. $\mathrm{Na}$ Paraíba, essa temática foi analisada levando-se em consideração as intervenções exercidas por pequenos produtores, por algumas ONGs e pelo Estado em localidades de três municípios, através das suas consequências para a vegetação de caatinga e para os solos. Para a identificação desses efeitos, foram selecionadas parcelas e transectos de $50 \mathrm{~m} \times 4 \mathrm{~m}$ em algumas propriedades, em situações de preservação e degradação. Foi identificada a quantidade de espécies vegetais presentes, a altura e as famílias às quais pertenciam, além de se realizar coletas de solos para identificar a sua fertilidade. Os resultados obtidos demonstraram que onde as ONGs pesquisadas estavam atuando $\mathrm{e}$ as suas orientações eram seguidas, o uso das terras pelos pequenos agricultores resultou em menor dano ambiental e sustentabilidade, enquanto nas áreas onde ocorria o manejo das propriedades de forma tradicional, sendo estas exclusivamente dependentes das ações do Estado, este se mostrou ausente quanto ao desenvolvimento de intervenções que levassem ao uso sustentável dessas terras, encontrando-se uma situação de elevada degradação.

Palavras-Chave: Desertificação, Caatinga, Fertilidade dos Solos.

\section{USE OF VEGETATION AND SOIL IN AREAS SUSCEPTIBLE TO DESERTIFICATON IN PARAIIBA STATE/BRAZIL}

Abstract: Desertification is a type of degradation occuring in dry climate zones around the world, mainly as a result of some actions due to the economic use of land in these areas. In Paraiba, state of Northeast Brazil, this theme was analyzed taking into account the interventions carried out by small producers, for some NGOs and Government in three cities, through its consequences for caatinga vegetation and soils. These effects were identified through the selection of plots and transects of $50 \mathrm{~m} \mathrm{x} 4 \mathrm{~m}$ on some properties in situations of preservation and decay. It was identified 
the number of species of plants presented, the height and the families which they belonged to, besides some soil sampling to identify its fertility was done. The results showed that where the NGOs surveyed were working and their guidelines were followed, the use of land by small farmers resulted in less damage to the environment and sustainability, while in areas where there was the management of properties in the traditional manner, which are exclusively dependent of the State's actions, this proved to be absent in the development of interventions that would lead to sustainable use of these lands, where a high state of degradation was found.

Keywords: Desertification, Caatinga, Soil Fertility.

\section{BIBLIOGRAFIA}

ANDRADE, L. A.; PEREIRA, I. M.; LEITE, U. T.; BARBOSA, M. R. V. 2005. Análise da cobertura de duas fitofisionomias de caatinga, com diferentes históricos de uso, no município de São João do Cariri, Estado da Paraíba. Cerne, Lavras (MG), v. 11, no 3, pp. 253-262, jul/set.

BRASIL. 1972. Levantamento Exploratório-Reconhecimento de Solos do Estado da Paraíba. Rio de Janeiro: Ministério da Agricultura/Sudene.

. 2004. Programa de Ação Nacional de Combate à Desertificação e Mitigação dos Efeitos da Seca/PAN-Brasil. Brasília: Ministério do Meio Ambiente/Secretaria de Recursos Hídricos.

CARVALHO, L. D. 2004. A emergência da lógica da "Convivência com o Semi-Árido" e a construção de uma nova territorialidade. Educação para a convivência com o semi-árido. Reflexões teórico-práticas. Juazeiro: Secretaria Executiva da Rede de Educação do Semi-Árido Brasileiro, pp. 13-27.

CCD. 1995. Convenção das Nações Unidas de Combate à Desertificação. Tradução: Delegação de Portugal. Lisboa: Instituto de Promoção Ambiental.

EMBRAPA. 2006. Sistema Brasileiro de Classificação de Solos. Embrapa Solos: Rio de Janeiro.

GIULIETTI, A. M.; BOCAGE-NETO, A.; CASTRO, A. J.; GAMARRAROJA, C. F. L.; SAMPAIO, E. V. S. B.; QUEIROZ, L.; FIGUEIREDO, A.; RODAL, M. J.; BARBOSA, R. V.; HARLEY, R. M. 2002. Espécies 
endêmicas da caatinga. In: SAMPAIO, E. V. S. B.; GIULIETTI, A. M.; VIRGÍNIO, J.; GAMARRA-ROJA, C. F. L. (eds.). Vegetação e Flora da caatinga. Recife: Associação Plantas do Nordeste, pp. 103-108.

JORGE, J. A. 1972a. Fósforo. In: MONIZ, A. C. (coord.). Elementos de Pedologia. São Paulo: Polígono/Ed. da Universidade de São Paulo, pp. 191-197.

1972b. Matéria Orgânica. In: MONIZ, A. C. (coord.). Elementos de Pedologia. São Paulo: Polígono/Ed. da Universidade de São Paulo, pp. 169-178.

LEPRUN, J. C. 1981. A erosão, a conservação e o manejo do solo no Nordeste brasileiro. Balanço, diagnóstico e novas linhas de pesquisa. Recife: SUDENE.

LUNA, R. G. 1998. Microbiota edáfica e fitocenose como indicadores de degradação ambiental do semi-árido paraibano. 120 p. Programa de PósGraduação em Desenvolvimento e Meio Ambiente - Mestrado, UFPB, João Pessoa (PB).

MESSIAS, A. S.; SILVA, D. J.; FREIRE, F. J.; SILVA, M. C. L. 2008. Fertilizantes. In: CAVALCANTI, F. J. A. (coord.). Recomendações de adubação para o Estado de Pernambuco: $2^{\mathrm{a}}$ aproximação. Recife: IPA, pp. 89-103.

PEREIRA, I. M.; ANDRADE, L. A.; SAMPAIO, E. V. S. B.; BARBOSA, M. R. V. 2003. Use-history effects on structure and flora of caatinga. Biotropica, v. 35, n.2, pp. 154-165.

ROXO, M. J. 2006. O panorama mundial da desertificação. MOREIRA, E. (Org.). Agricultura familiar e Desertificação. João Pessoa: Ed. Universitária da UFPB, p. 11-32.

SÁ, I. B.; FOTIUS, G. A.; RICHÉ, G. R. 1994. Degradação ambiental e reabilitação natural no trópico semi-árido brasileiro. Conferência Nacional e Seminário Latino-Americano da Desertificação. Fortaleza: Esquel/PNUD/Governo do Ceará/BNB, 7-11.

SAMPAIO, E. V. S. B.; ARAÚJO, M. S. B.; SAMPAIO, Y. S. B. 2005. Propensão à desertificação no semi-árido brasileiro. Revista de Geografia do Departamento de Ciências Geográficas da UFPE, Recife (PE), v. 22, n. 02, pp. 67-80.

SILVEIRA, M. M. L.; ARAÚJO, M. S. B.; SAMPAIO, E. V. S. B. 2006. Distribuição de fósforo em diferentes ordens de solo do semi-árido da Paraíba e de Pernambuco. Revista Brasileira de Ciência do Solo, Viçosa (MG), v. 30, n. 2, pp. 1-13. 
SOUZA, B. I. 2008. Cariri paraibano: do silêncio do lugar à desertificação. 198 p. Programa de Pós-Graduação em Geografia Doutorado, UFRGS, Porto Alegre (RS).

Revista GEOgraphia - UFF

Data de submissão do artigo: 31/05/11 